\title{
Does Calcium Supplementation with or without Vitamin D Increase the Risk of Cardiovascular Disease?
}

\author{
D Vitamini ile Birlikte veya Tek Başına Kalsiyum Takviyesi \\ Kardiyovasküler Hastalık Riskini Artırır mı?
}

\author{
Haydar GÖK \\ Department of Physical Medicine and Rehabilitation, Medical Faculty of Ankara University, \\ Cebeci Research and Application Hospital, Ankara, Turkey
}

Calcium supplements are widely prescribed to elderly people, particularly postmenopausal women, to maintain their bone health. However, there is emerging data from various studies that long-term use of calcium supplements in healthy older adults could cause an increased cardiovascular risk, especially for myocardial infarction (MI).

Over the past two decades there has been a growing body of evidence supporting the beneficial effects of calcium supplements for lipid metabolism and protection against vascular disease. Townsend et al., ${ }^{[1]}$ analyzed the first, third and fourth National Health and Nutrition Examination Surveys (NHANES) and found that a dietary pattern low in mineral intake, specifically calcium, potassium, and magnesium, was associated with hypertension in American adults. In a study researching the effects of calcium supplementation on serum lipids or body composition in healthy older men, the authors found no significant effects and concluded that calcium supplementation in those with low dietary intake may offer benefits for blood pressure control. ${ }^{[2]}$ Despite these favorable results, the latest data, based on two recent meta-analyses of clinical trials, have suggested that calcium supplements might actually increase a person's risk of having MI. ${ }^{[3,4]}$ Bolland et al. ${ }^{[3-5]}$ reported that calcium supplements increase the risk of MI and stroke by $25-30 \%$ and $15-20 \%$, respectively.
In their meta-analysis, Bolland et al. ${ }^{[3]}$ concluded, "Calcium supplements without vitamin D are associated with an increased risk of MI." However, some investigators have raised concerns about various aspects of this study. ${ }^{[6-8]}$ The same authors also examined the effect of calcium supplements, either with or without vitamin $\mathrm{D}$, on the risk of cardiovascular events in a meta-analysis and came to the following conclusion: "Calcium supplements with or without vitamin D modestly increase the risk of cardiovascular events, especially MI."[4] According to Reid et al., ${ }^{[9]}$ the increased cardiovascular risk is not mitigated by co-administration of vitamin $\mathrm{D}$, and the number of cardiovascular events caused is likely to be greater than the number of fractures prevented.

Similar results were reported in another epidemiological study done on 24.000 people from Heidelberg, Germany In which Li et al., ${ }^{[10]}$ found an $86 \%$ increase in MI among people who took calcium supplementation regularly compared with those who took no supplements. They suggested that "Increasing dietary calcium intake from (the) diet might not confer significant cardiovascular benefits, while calcium supplements, which might raise MI risk, should be taken with caution."

Recently, Lewis et al. ${ }^{[1]}$ investigated the association of calcium supplementation and the risks 
of atherosclerotic vascular disease in older women in a five-year RCT study with a 4.5-year follow-up. They reported that calcium supplements had no effect on the incidence of atherosclerotic vascular disease. However, the generalizability of these results might be limited due to insufficient power and the choice of a composite endpoint. In a systematic review, Wang et al. ${ }^{[12]}$ concluded that "Secondary analyses in existing trials to date suggest a neutral effect of calcium (with or without vitamin D) supplements on cardiovascular events, but do not allow for a definitive conclusion." Together with other authors, they emphasized the need for randomized clinical trials that will test the effect of calcium supplementation on cardiovascular disease (CVD) as its primary endpoint. ${ }^{[12,13]}$ However, according to Reid et al., ${ }^{[14]}$ "Patients and clinicians must make their judgments of benefit and risk based on the currently available data because of the practical and ethical barriers to carrying out a study where the primary hypothesis is one of harm." They suggested optimizing calcium intake from the diet instead of supplementation, and using agents of proven antifracture efficacy in patients with osteoporosis.

Currently, a proven mechanism of calcium supplements which possibly increases the risk of CVD is absent. Importantly, supplemental calcium, and not dietary calcium, seems to increase the risk of cardiovascular events. ${ }^{[1]}$ Compared to dietary intake with slower absorption, calcium supplements are known to increase serum calcium to a modest degree. It has been hypothesized that abrupt changes in concentrations of calcium in the blood with calcium supplementation might contribute to adverse cardiovascular effects.

In conclusion, the current totality of evidence indicates an association between calcium intake and cardiovascular risk, while not necessarily providing a cause-and-effect relationship. While further studies are needed, calcium supplements should be used only for those patients for which the potential benefits outweigh the possible risks.

\section{REFERENCES}

1. Townsend MS, Fulgoni VL 3rd, Stern JS, Adu-Afarwuah $\mathrm{S}, \mathrm{McCarron}$ DA. Low mineral intake is associated with high systolic blood pressure in the Third and Fourth National Health and Nutrition Examination Surveys: could we all be right? Am J Hypertens 2005;18:261-9.

2. Reid IR, Ames R, Mason B, Bolland MJ, Bacon CJ, Reid $\mathrm{HE}$, et al. Effects of calcium supplementation on lipids, blood pressure, and body composition in healthy older men: a randomized controlled trial. Am J Clin Nutr 2010;91:131-9.

3. Bolland MJ, Avenell A, Baron JA, Grey A, MacLennan GS, Gamble GD, et al. Effect of calcium supplements on risk of myocardial infarction and cardiovascular events: metaanalysis. BMJ 2010;341:c3691. doi: 10.1136/bmj.c3691.

4. Bolland MJ, Avenell A, Baron JA, Grey A, MacLennan GS, Gamble GD, et al. Effect of calcium supplements on risk of myocardial infarction and cardiovascular events: metaanalysis. BMJ 2010;341:c3691. doi: 10.1136/bmj.c3691.

5. Bolland MJ, Barber PA, Doughty RN, Mason B, Horne A, Ames R, et al. Vascular events in healthy older women receiving calcium supplementation: randomised controlled trial. BMJ 2008;336:262-6.

6. Dawson-Hughes B. Calcium and heart attacks. The heart of the matter. BMJ 2010;341:c4993. doi: 10.1136/bmj. c4993.

7. Heiss G, Hsia J, Pettinger M, Howard BV, Anderson G. Calcium and heart attacks. No evidence for increased risk. BMJ 2010;341:c4995. doi: 10.1136/bmj.c4995.

8. Nordin BE, Daly RM, Horowitz J, Metcalfe AV. Calcium and heart attacks. Making too much of a weak case. BMJ. 2010;341:c4997. doi: 10.1136/bmj.c4997.

9. Reid IR, Bolland MJ, Sambrook PN, Grey A. Calcium supplementation: balancing the cardiovascular risks. Maturitas 2011;69:289-95.

10. Li K, Kaaks R, Linseisen J, Rohrmann S. Associations of dietary calcium intake and calcium supplementation with myocardial infarction and stroke risk and overall cardiovascular mortality in the Heidelberg cohort of the European Prospective Investigation into Cancer and Nutrition study (EPIC-Heidelberg). Heart 2012;98:920-5. doi:10.1136/heartjnl-2011-301345.

11. Lewis JR, Calver J, Zhu K, Flicker L, Prince RL. Calcium supplementation and the risks of atherosclerotic vascular disease in older women: results of a 5-year RCT and a 4.5-year follow-up. J Bone Miner Res 2011;26:35-41. doi: 10.1002/jbmr.176.

12. Wang L, Manson JE, Sesso HD. Calcium intake and risk of cardiovascular disease: a review of prospective studies and randomized clinical trials. Am J Cardiovasc Drugs 2012;12:105-16. doi: 10.2165/11595400-000000000-00000.

13. Hennekens $\mathrm{CH}$, Barice EJ. Calcium supplements and risk of myocardial infarction: a hypothesis formulated but not yet adequately tested. Am J Med 2011;124:1097-8.

14. Reid IR, Bolland MJ, Grey A. Calcium supplements and risk of myocardial infarction: an hypothesis twice tested. Am J Med 2012;125:e15. doi:10.1016/j.amjmed.2011.09.006. 